\title{
Promising use of Polymerase Chain Reaction Associated to Reverse Transcription for the Detection ofthe America-1 Lineage of Canine Distemper Virus \\ Correa.V, Céspedes .PF, Navarro .C
}

\author{
Animal Preventive Medicine Department, Animal and Veterinary Sciences Faculty, University of Chile \\ *Corresponding Author: Navarro. C, Animal Preventive Medicine Department, Animal and Veterinary \\ Sciences Faculty, University of Chile, Email: canavarr@uchile.cl
}

\begin{abstract}
Canine Distemper (CD) is one of the pathologies that causes the highest rate of morbidity and mortality in domestic canines worldwide and also represents an important disease in several families of terrestrial mammals: Canidae, Procyonidae, Mustelidae, Mephitidae, Hyaenidae, Ursidae ,Ailuridae, Viverridae, Felidae and some marine mammals the cape seal (pusacaspica). This disease is caused by Canine Distemper virus (CDV), a single-stranded RNA virus and negative polarity, whose genome consists of six genes, codes for six structural proteins. Among them, the Hemagglutinin encoded by the $H$ gene, has the highest amino acid variability, induces the production of neutralizing antibodies synthesized by the host immune system. Based on the variability of the H gene, it has been described that worldwide there would be at least fourteen lineages different from the CDV and in our country has been described the presence of at least two lineages circulating among our sick dogs with the pathology: America-1 and Europe.
\end{abstract}

Thus, the objective of this report was to implement the detection of the America-1 lineage of the Canine Distemper Virus by means of the Polymerase Chain Reaction associated with reverse transcription (RT-PCR) by means of in silico-designed primers. For this, the access numbers of the described nucleotide sequences were used in a phylogenetic tree constructed using the CDV H gene as target (Ke et al., 2015) and stored in the Genbank® database,

The designed primers were found to be effective for CDV detection and the RT-PCR was able to detect a specific fragment of the $H$ gene from the positive samples, therefore it could be suggested that these in silicodesigned primers can effectively be used to detect the America-1 lineage.

Keywords: DC, CDV, America-1 lineage, Gen H, primers, in silico, RT-PCR.

\section{INTRODUCTION}

Canine Distemper (CD) is one of the main diseases that affects domestic canines and causes high morbidity and mortality rates in unvaccinated dogs. In recent years it has been observed in the clinic that animals vaccinated in the same way are catching the virus. Canine Distemper Virus (CDV) also affects common and endangered species of wild animals throughout the world. Domestic dogs and other related species serve as reservoirs of the virus and play an important role in the transmission of the disease (Chinnadurai et al., 2017). CDV can affect many species, the younger ones being more susceptible, because they have lost maternal antibodies and their immune system is still immature to respond to infection (Martella et al., 2008). The genome of the virus encodes six structural proteins: nucleocapsid protein encoded by the $\mathrm{N}$ gene, membrane protein encoded by the $\mathrm{M}$ gene, phosphoprotein encoded by the $\mathrm{P}$ gene, large polymerase encoded by the $\mathrm{L}$ gene, hemagglutinin encoded by the $\mathrm{H}$ gene and the fusion protein encoded by the $\mathrm{F}$ gene (Martella, et al., 2008). CDV lineages have been described based on the analysis of the Hemagglutinin $(\mathrm{H})$ gene, this gene has the highest degree of variability. At present, 14 types of lineages have been determined according to this gene, identified as America-1 (vaccine strain), America-2, Asia-1, Asia-2, Asia-3 and Asia-4, Europe1/South America-1 (EU-1 / SA-1), Arctic, European Wild (EW), South America-2 (SA-2), South America-3 (SA-3), Rockborn-like (RL), Africa-1 and Africa -2 (Ke et al., 2015). In Chile, it was determined through an analysis of a region of the $\mathrm{H}$ gene, that at least two circulating lineages would exist in the country's canine population: America 1 and Europe 1 (Salas et al., 2018). Because DC is a highly contagious disease, lethal and affecting many species, it is very important to implement a technique that allows antemortem viral detection and thus facilitate diagnosis and early treatment. Thus, in this report specific in silico primers were designed for the América-1 lineage of 
the CDV $\mathrm{H}$ gene, using the Polymerase Chain Reaction (PCR), prior reverse transcription. The expected result would allow positioning the $\mathrm{H}$ gene as a detection target despite the variability described.

\section{BACKGROUNDS}

\subsection{Ethiology}

The Canine Distemper Virus (CDV) is classified in the Mononegavirales order, Paramyxoviridae family and Morbillivirus genus (Amarasinghe et al., 2018). It is a pleomorphic virus, has a lipid envelope and a diameter of 150 to $300 \mathrm{~nm}$. (Summers and Appel, 1994). Its genome consists of about 15.7 kilobases $(\mathrm{kb})$, consisting of a single strand of RNA of negative polarity, not segmented, which codes for six structural proteins: nucleocapsid protein $(\mathrm{N}$ gene, $1.5 \mathrm{~kb})$, the membrane protein $(\mathrm{M}$ gene, $1 \mathrm{~kb}$ ), two proteins associated with transcriptase: the phosphoprotein (P gene, $1.5 \mathrm{~kb}$ ), the large polymerase (L gene, $6.5 \mathrm{~kb}$ ), two types of glycoproteins; hemagglutinin (gene $\mathrm{H}, 1.8 \mathrm{~kb}$ ) and the fusion protein (gene F, $1.9 \mathrm{~kb}$ ) (Martella, et al., 2008; Céspedes et al., 2010). Proteins F and H, located in the lipid envelope, induce the production of neutralizing antibodies synthesized by the host's immune system (Appel and Summers, 1995). The helical nucleocapsid contains the N, P and L proteins, which initiate intracellular replication. The $\mathrm{M}$ protein connects the glycoproteins of the surface and the nucleocapsid during viral maturation (Beineke et al., 2009). The large polymerase protein $(\mathrm{L})$ is the fundamental subunit of the polymerase RNA complex given its catalytic effect in the synthesis of viral RNA. (Lamb and Parks, 2007).

\subsection{Host Range of the Canine Distemper Virus}

The CDV hosts include numerous families of the order of carnivores such as Canidae (dogs, foxes, wolves among others), Procyonidae (raccoons, coati), Mustelidae (ferret, weasel, mink, among others), Mephitidae (skunks), Hyaenidae ( hyenas), Ursidae (bears), Ailuridae (red pandas), Viverridae (genets, civets) and Felidae (tigers, lions, leopards, jaguars, with the exception of the domestic cat) (Martella et al., 2008; Chinnadurai et al., 2017. Yipeng, et al., 2017). In addition, it has been detected in some marine mammals such as the cáspica seal (pusa caspica) (Kuiken et al., 2006).

\subsection{Pathogenesis}

The main routes of entry of the virus are ocular, nasal and oral, through secretions, aerosols and fomites, reaching mucosal surfaces (von Messling et al., 2005). CDV is a lymphotropic and highly immunosuppressive virus (Pinotti et al., 2009). Rapid replication begins in local lymph nodes and in seven days to all lymphatic tissues (primary viremia), producing early infection of lymphocytes and mononuclear cells, by blocking the synthesis and signaling pathways of interferons and cytokines, decreasing the proliferation of $\mathrm{B}$ and $\mathrm{T}$ lymphocytes, the latter being more affected, resulting in severe immunosuppression of the host (von Messling et al., 2005). During the second and third week after infection, some dogs initiate a strong humoral and cellular immune response and can recover without clinical signs later, while others develop a weak immune response and present acute or subacute disease, because the lymphocytes and mononuclear cells infected carry the virus to the epithelial surface of the digestive, respiratory, urogenital, skin and / or central nervous system, with the respective clinical signs (secondary viremia) (Appel and Summers, 1999). In the Central Nervous System (CNS) the virus replicates initially in neurons and in glial cells, it can cause lesions in the white matter and in the gray matter. In a chronic course of infection, due to a deficient immune response or a delayed response, characteristic demyelinating inflammatory lesions are described (BSAVA, 2013).

\subsection{Clinical Signs}

$\mathrm{CD}$ has different clinical presentations that can vary from acute, subacute to chronic, where the respiratory, digestive and nervous systems are affected (Martella, et al., 2008). The severity of the clinical signs observed depends on different factors such as the virulence of the infecting virus, environmental conditions, the age of the host and their immunological status (BSAVA, 2013).

Systemic signs include anorexia, dehydration, fever and oculo-nasal serous discharge. Neurological signs include myoclonus, ataxia, tremor, seizures, visual deficit and vestibular dysfunction. 
Neurological signs may be caused directly by the virus or may occur as a result of the immune response against the CNS, in which case the animals have a level of intermediate immunity and CNS involvement may develop months or years later (Gamiz et al., 2011; BSAVA, 2013).

\subsection{Treatment}

Due to the lack of specific antivirals and standardized protocols, the treatment used consists of a symptomatic therapy, support care (hydroelectrolytic fluids, vitamin and nutritional supplements) and antibiotics to prevent secondary bacterial infections, common in immunocompromised animals (Appel and Summers, 1999; Martella et al., 2008, Pinotti et al., 2009).

\subsection{Prevention and Control}

Vaccination is the main strategy to prevent and control the disease. Vaccines with live attenuated virus (VVA) stimulate the humoral and cellular immune response and induce immunological memory (Martella et al., 2008). The development and use of these vaccines have contributed to a drastic reduction in the incidence of DC in domestic dogs (Appel and Summers, 1999). Despite this, outbreaks of the disease have been observed in populations of immunized dogs belonging to different geographic regions (BSAVA, 2013). These outbreaks could be explained by the reversal of the virulence of the attenuated strains, by the emergence of new strains sufficiently variable to evade the immune response generated by the vaccines, failures in the administration of the vaccines, or, due to the immunological state of the animal (Salas et al., 2018).

\subsection{Diagnosis}

The diagnosis of DC is based on the clinical suspicion supported by the manifestation of clinical signs and the antecedents of risk predisposing to the disease (Martella et al., 2008). However, the lack of specificity in the symptoms associated with the infection can lead to confusion with other pathologies in the final diagnosis, for which various complementary diagnostic methodologies have been developed, including serological techniques (immunohistochemistry and ELISA). and molecular techniques (Polymerase Chain Reaction prior reverse transcription (RT-PCR) (Pinotti et al., 2009).

\subsection{PCR and the RT-PCR Variant}

The PCR technique was developed in the eighties and since then it has revolutionized molecular genetics, making possible the study of a wide range of genes. It has been used in multiple areas where the immense potential of PCR to amplify minimal amounts of DNA (or RNA) has been particularly attractive (Murphy et al., 1999). Recently it has been applied successfully, since it is a highly specific, rapid and sensitive method for the antemortem diagnosis of CDV infection, independently of the presentation of the disease, the humoral immune response, and the distribution of the viral antigen (Frisk et al., 1999; Pardo et al., 2005; Navarro, 2012). Thus, to apply this technique from RNA, it is necessary to do a reverse transcription before starting the amplification by PCR, this will generate a complementary DNA (cDNA), which will be the substrate for PCR (Elia et al., 2006 ).

\subsection{Lineages}

Through RT-PCR, the existence of at least 14 CDV lineages based on the nucleotide sequence of the $\mathrm{H}$ gene has been established worldwide (Asia 1, Asia 2, Asia 3, Asia 4, America 1, America 2, Arctic, Europe 1/South America 1, South America 2, South America 3, Wild European, Africa 1, Africa 2 and Rockborn-like) (Ke et al., 2015).

In Chile, in a study it was established by means of the analysis of a segment of the $\mathrm{H}$ gene that there would be at least two circulating lineages in the national canine population, indicating the lineages America-1 and Europa-1 as present in the country, where America-1 is genetically related to vaccinal strains (Salas et al., 2018)

As already established that in the country there are at least two types of lineages circulating among sick dogs with CD and one of those lineages is also used in vaccines, in this work the use of RT-PCR was proposed. primers designed in silico- for the detection of CDV using the lineage América-1 of the $\mathrm{H}$ gene as target.

Thus, with the success of this strategy, the presence of the virus can be established and directly determine if the sample analyzed belongs to this lineage, suggesting the discarding of nucleotide sequencing. 


\section{MATERIALS AND MethodS}

The present study was carried out in the Microbiology and Virology Laboratories of the Department of Preventive Medicine of the Faculty of Veterinary and Animal Sciences (FAVET) of the University of Chile.

\subsection{Design in Silico Primers for the Detection of the CDV Lineage América-1}

First, an official database of genetic sequences (Genbank $\left.{ }^{\circ}, 2018\right)$ was used to obtain the nucleotide sequences of the Latin-1 lineage of the CDV, as described in previous phylogenetic tree (Ke et al., 2015). Then, Clustal $\Omega$ software (2018), free access, was used to align sequences to determine nucleotide identity zones, thus obtaining the candidate sequences to be used for the design of primers. This design contemplates the use of free access software (OligoPerfect TM Designer, 2018). When there is more than one pair of candidate primers, the one that provided the best selection parameters was chosen, such as the percentage of GC and $\mathrm{Tm}$. The specificity of the primers was corroborated by the BLAST program. Once the sequence of the primers was obtained, their synthesis was commissioned to Fermelo ${ }^{\circledR}$ and the lyophilized primers were solubilized to a final concentration of 1 uM.

\subsection{Implement the RT-PCR Reaction Detection of the CDV America-1 Lineage}

The obtained primers were used in an RT-PCR reaction that contemplated the use of 20 samples of RNA positive to CDV (N gene) found in the laboratory, obtained from the blood of dogs with CDV compatible signology. The "SuperScript ${ }^{\mathrm{TM}}$ one step RT-PCR with PlatinumTaq" kit (Invitrogen ${ }^{\circledR}$ ) was used according to the manufacturer's instructions. Following the protocol proposed by the company, which consisted of $25 \mathrm{uL}$ of the component "2x Reaction Mix", which contains $0.4 \mathrm{mM}$ of each deoxyribonucleotide and $3.2 \mathrm{mM}$ of MgSO4, 2uL of "SuperScript. III RT / Platinum Taq Mix ", $5 \mathrm{uL}$ of each primer and $5 \mathrm{uL}$ of RNA annealing to reach a final volume of $50 \mathrm{uL}$.

RT-PCR protocol: a 96-well Apollo 96-well thermocycler was used and the retrotranscription stage of the RNA was favored in order to obtain the complementary DNA to be used in the next stage carried out according to the manufacturer's instructions: $45^{\circ} \mathrm{C}$ for 30 minutes and then $94^{\circ} \mathrm{C}$ for 2 minutes. The DNA denaturation phase was carried out at $94^{\circ} \mathrm{C}$ for 30 seconds. During the alignment phase a temperature of $53^{\circ} \mathrm{C}$ was used for 30 seconds and the elongation phase contemplated a temperature of $72^{\circ} \mathrm{C}$ for one minute. After 40 cycles, we proceeded to a final extension stage at $72^{\circ} \mathrm{C}$ for 8 minutes and then, we continued with the visualization of the amplified product.

Two samples typified as América-1 and European lineage was used as a positive an negative control, respectively (Salas et al., 2018 (Salas, 2013) and nuclease-free water was used as reagent control.

\subsection{Visualization of the DNA Fragment Synthesized in RT-PCR}

The products were visualized by means electrophoresis in $2 \%$ agarose gel in Tris-HC1 buffer (100 $\mathrm{mM}$ Tris-HC1, $10 \mathrm{mM}$ EDTA) and their path compared to a molecular size standard (AccuRuler 100bp Plus DNA Ladder, Maestrogen ${ }^{\circledR}$ ). $5 \mu \mathrm{L}$ of the PCR product was taken and mixed with $1 \mu \mathrm{L}$ of commercial loading product (Fermentas $\left.{ }^{\circledR}\right)$. Next, $90 \mathrm{~V}$ electrophoresis was performed for ninety minutes. After electrophoresis the gel was incubated with ethidium bromide $(0.5 \mu \mathrm{g} / \mathrm{mL})$ for thirty minutes, the DNA bands were visualized in an ultraviolet light transilluminator. Biosecurity measures. Use of clean material, disposal of waste and use of closed white apron and gloves during the development of practical work. Now of visualizing the gels, glasses with UV filter were used, and after use, the gels incubated in ethidium bromide were eliminated through the use of incineration, since the chemical has mutagenic properties (Saeidnia and Abdollahi, 2013).

\section{ReSUlts}

Design in silico primers for the detection of the America-1 CDV lineage.

\subsection{Obtaining Nucleotide Sequences}

The nucleotide sequences were obtained from the official database of genetic sequences (Genbank®, 2018), occupying the access numbers of the 11 nucleotide sequences (Table 1). 
Promising use of Polymerase Chain Reaction Associated to Reverse Transcription for the Detection of the America-1 Lineage of Canine Distemper Virus

Table1. Genbak® Access Numbers used to Obtain Common Nucleotide Zones for the America-1 Lineage

\begin{tabular}{|c|c|c|c|}
\hline Viral strain & $\begin{array}{l}\text { Access } \\
\text { number }\end{array}$ & $\begin{array}{c}\text { Isolation } \\
\text { year }\end{array}$ & $\begin{array}{c}\text { Geographic } \\
\text { location }\end{array}$ \\
\hline \multicolumn{4}{|l|}{ America-1 } \\
\hline AF378705_30_ZA_Onderstepoort_Fox & AF378705 & $1930 \mathrm{~s}$ & USA \\
\hline Z35493_4O_US_Convac_Dog & 235493 & $1930-1950$ & USA \\
\hline AF259552_40_US_SnyderHill_Dog & AF259552 & $1930-1950$ & USA \\
\hline DQ903854_51_US_Lederle_Dog & DQ903854 & 1951 & USA \\
\hline AY548109_98_US_2655_Raccoon & AY548109 & 1998 & USA \\
\hline HMO46486_O7_KZ_Phoca_Seal & HMO46486 & 2007 & Kazakstan \\
\hline HM063009_89_KZ_Shuskiy_Mink & HMO63009 & 1989 & Kazakstan \\
\hline KM926612_92_CN_L_Fitchew & KM926612 & 1992 & China \\
\hline DQ778941_O6_CN_CDV3_Mink & DQ778941 & 2006 & China \\
\hline GQ332531_O8_CN_16_Dog & GQ332531 & 2008 & China \\
\hline HQ403645_O9_CN_GZ1_Dog & HQ403645 & 2009 & China \\
\hline
\end{tabular}

\subsection{Alignment of Sequences}

The Clustal $\Omega$ software was used for the alignment of sequences and the nucleotide identity zones were determined. In this way, we obtained the candidate sequences to be used for the design of primers as shown in Table 2, where the alignment of the eleven nucleotide sequences is demonstrated, and in the areas where there are zones of nucleotide identity it is shown with an asterisk at the end of each column.

Table2. Example of the use of the Clustal Program $\Omega$ and of the alignment of common candidate sequences to obtain primers.

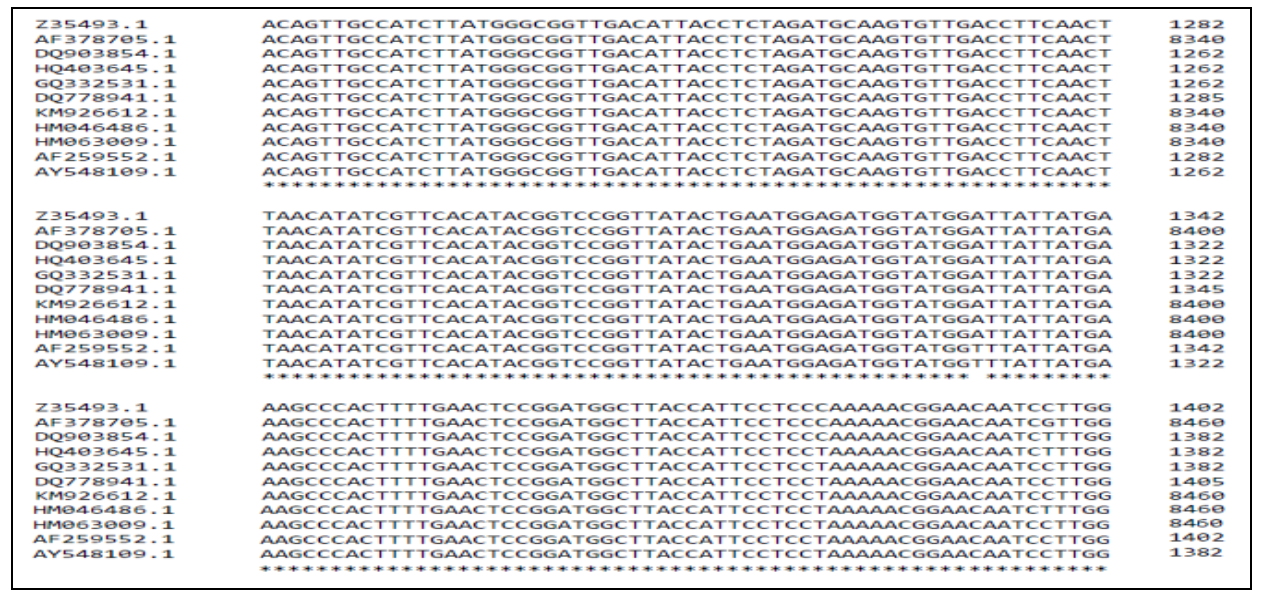

\subsection{Primers Design}

There were several segments of the genome with areas with nucleotide identity zones, however, the primers that could be obtained from these sequences had a low percentage of guanine-cytosine, generated smaller amplicons, the fusion temperature was very variable among the partisans and some of those primers could be united to several lineages of the CDV. For this reason, the zone indicated in Table 3 was chosen, where the one that provided the best selection parameters, such as the percentage of GC and Tm, was chosen. The primers would allow obtaining an amplicon of about 556 base pairs (bp).

Table3. Use of the OligoPerfect Design ${ }^{\circledR}$ Program by Invitrogen for the in vitro design of CDV primers

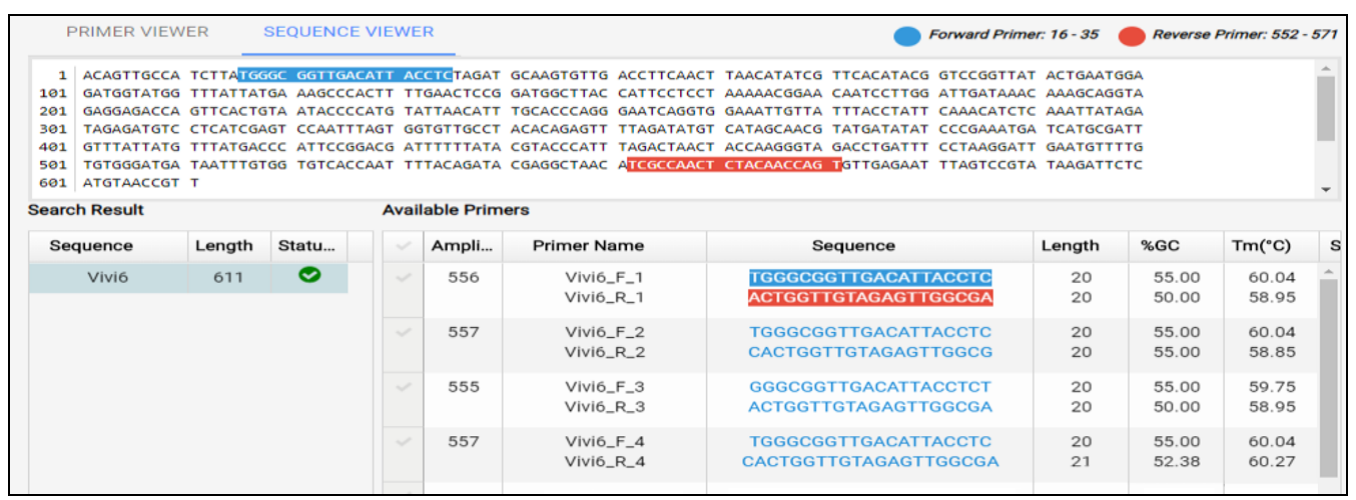




\subsection{Primer Specificity}

The specificity of the primers was corroborated by the BLAST program. Where it was indicated that both primers can be joined to CDV sequences. Once the sequence of the primers was obtained and the BLAST was made to each of the primers, Fermelo ${ }^{\circledR}$ was commissioned for its synthesis. Objective 2 Implement the RT-PCR reaction for the detection of the América-1 lineage of the CDV. With the procedure indicated in Material and Method, unique and clear DNA bands between 500 and $600 \mathrm{bp}$ were visualized for the positive control (CDV lineage America-1) and in the 20 positive samples to $\mathrm{CDV}$ according to the $\mathrm{N}$ gene. No bands were observed in the lanes corresponding to the negative control (CDV European lineage) or in the control of reagents (Figure 1).

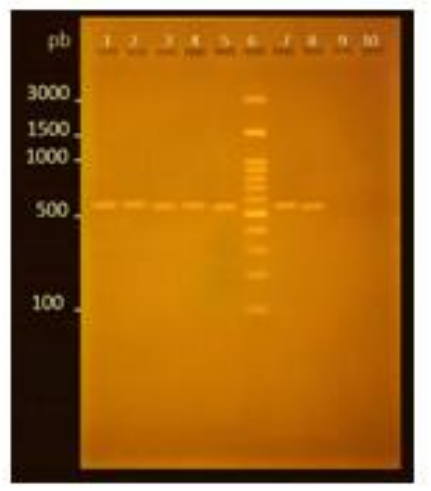

Fig1. Gel electrophoresis 2\% agarose

Lane 1: Control (+) lineage America 1; Lane 2: sample 1; Lane 3: sample 5; Lane 4: sample 8; Lane 5: sample 10; Lane 6: MTM; Lane 7: sample 14; Lane 8: sample 17; Lane 9: control (-) European lineage; Lane 10: reagent control; MTM: Maestrogen ${ }^{\circledR}(100-3000 \mathrm{bp})$

To corroborate the negative sample (European lineage) and to eliminate the possibility of degradation of the RNA involved, an RT-PCR was additionally performed to detect the $\mathrm{N}$ gene according to the protocol previously established in this laboratory (Muñoz, 2013). Clear and unique DNA bands of a size close to $300 \mathrm{bp}$ are observed and no nonspecific bands are observed (Figure 2).

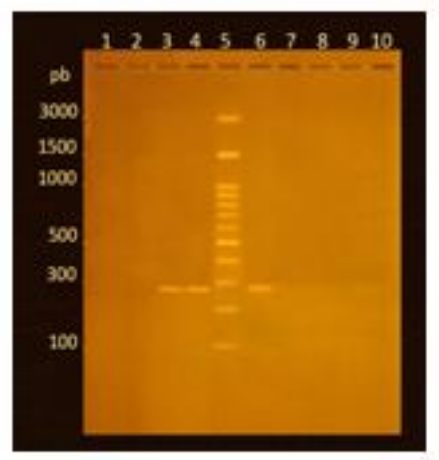

Fig2. Gel electrophoresis Agarose 2\%.

Lane 1: Control (-); Lane 2: control of reagents; Lane 3: control (+) European lineage.

Lane 4: control (+) lineage America. Lane 5: MTM; Lane 6: sample 19; Lanes 7-10: without loading. MTM: Maestrogen ${ }^{(100-3000 ~ b p) . ~}$

\section{DISCUSSION}

The $\mathrm{H}$ gene is one of the six genes that make up the CDV genome and codes for the glycoprotein Hemagglutinin, which in addition to generating the immune response in the body (Appel and Summers, 1995), has the highest antigenic and genetic variability, presenting around of $10 \%$ variability between different lineages. Therefore, several authors describe it as a gene not suitable for the molecular diagnosis of the virus (Gallo et al., 2007, Martella et al., 2008).

In the Faculty of Veterinary and Animal Sciences of the University of Chile, two reports were made that used the $\mathrm{H}$ gene as a detection target in the RT-PCR technique (Jara et al., 2018, Salas et al., 
2018). In the first, five out of six stored samples with a week old and none of the 20 oldest samples stored were amplified. In the second, three of the 42 samples analyzed by its protocol were amplified. In both cases, the sensitivity of their RT-PCR protocols was low, from which it could be inferred that these results were obtained due to the primers used and described in previous studies (Mochizuki et al., 1999; Pardo, 2006).

In this work, an RT-PCR protocol with primers designed in silico was used, using the $\mathrm{H}$ gene as a detection target and a fragment of about 556 bp was amplified in the 20 samples positive to CDV according to the $\mathrm{N}$ gene. Negative samples were the existence of degraded RNA samples; however, negative samples were corroborated as intact RNA samples by applying an RT-PCR with primers for the $\mathrm{N}$ gene (Figure 2).

According to these results, the protocol used in this Title Memory could be used in samples suspicious to CDV, to be able to define if this protocol has high sensitivity and specificity to detect CDV lineage América-1. The specificity of busy primers could also be corroborated using other programs such as Vector NTI or DS gene. However, to corroborate the sensitivity of the method implemented, additional studies are required.

It is recommended to obtain the nucleotide sequences of the DNA fragments obtained from the samples, to compare them with CDV isolates available in GenBank ${ }^{\circledR}$, in this way it will be possible to confirm that the samples do indeed belong to the América-1 lineage.

\section{CONCLUSION}

The molecular test implemented represents a rapid and specific ante-mortem diagnostic method for Canine Distemper disease, which is effective for the detection of CDV. The RT-PCR was able to detect a specific fragment of the CDV $\mathrm{H}$ gene from the positive samples, therefore it could be suggested that these in silico designed primers can effectively be occupied to detect the America-1 lineage

\section{REFERENCES}

[1] Amarasinghe, G.; Aréchiga-Ceballos, N.; Banyard, A., Basler, C.; Bavari, S.; Bennett, A. 2018. Taxonomy of the order mononegavirales: update 2018. Arch. virol. doi: 10.1007/s00705-018-3814-x.

[2] Appel, M.; Summers, B. 1995.Pathogenicity of morbilliviruses for terrestrial carnivores. Vet. Microbiol. 44: 187-191.

[3] Appel, M.; Summers, J. 1999. Distemper canino: estado actual. Institute for Animal Health, College of Veterinary Medicine, Cornell University, Ithaca, New York, USA. 5p

[4] Beineke, A.; Puff, C.; Seehusen, F.; Baumgartner, W.2009. Pathogenesis and immunopathology of systemic and nervous canine Distemper. Vet. Immunol. Immunop. 127: 1-18.

[5] British Small Animal Veterinary Association (BSAVA).2013. Manual of canine and feline neurology. $3^{\mathrm{a}}$ ed. Barcelona, Lexus. $610 \mathrm{p}$

[6] Céspedes, P.; Cruz, P.; Navarro, C. 2010. Modulación de la respuesta inmune durante la infección por virus distemper canino: implicancias terapéuticas y en el desarrollo de vacunas. Arch. Med. Vet. 42:15-28.

[7] Chinnadurai, S.; Kinsel, M.; Adkesson, M.; Terio, K. 2017. Canine distemper in a vaccinated snow leopard (Panthera uncia). J. Zoo Wildlife Med. 48(4): 1200-1203.

[8] Clustal S.2018. Multiple Sequence Alignment. [available] http://www.ebi.ac.uk/Tools/msa/clustalo/ [march 18, 2018]

[9] Elia, G.; Decaro, N.; Martella, V.;Cirone, F.; Lucente, M.; Lorusso, E.; Trani, L.; Buonavoglia, C. 2006. Detection of canine distemper virus in dog by real-time RT-PCR. J. Virol. Meth. Vol. 136. 1-2: 171-176.

[10] Frisk, A.; König, M.; Moritz, A.; Baumgärtner W. 1999. Detection of canine distemper virus nucleoprotein RNA by reverse transcription-PCR using serum, whole blood, and cerebrospinal fluid from dogs with distemper. J. Clin. Microbiol. 37: 3634- 3643.

[11] Gallo, M.; Remorini, P.; Periolo, O.; Iglesias, M.; Mattion, N.; La Torre, J. 2007. Detection by RT-PCR and genetic characterization of canine Distemper virus from vaccinated and non-vaccinated dogs in Argentina. Veterinary Microbiology 125: 341-349.

[12] Gamiz, C.; Martella, V.; Ulloa, R.; Fajardo, R.; Quijano-Hernandez, I.; Martinez, S.2011. Identification of a new genotype of canine distemper virus circulating in America. Vet. Res. Commun. 35:381-390. 
[13] Genbank, 2018. NIH genetic sequence database [Available] https://www.ncbi.nlm.nih.gov/genbank/ [April 12, 2018]

[14] Jara P, Céspedes PF,, Navarro, C. 2018. Canine Distemper Virus detection based in Hemaglutinine Gene as target in Reverse Transcriptase-Polymerase Chain Reaction. Insights Vet Sci. 2018; 2: 034-041.

[15] Kuiken, T.; Kennedy, S.; Barrett, T.; Van De Bildt, M.; Borgsteede, F.; Brew, S.; Codd, G.; Duck, C.; Deaville, R.; Eybatov, T.; Forsyth, M.; Foster, G.; Jepson, P.; Kydyrmanov, A.; Mitrofanov, I.; Ward, C.; Wilson, S.; Osterhaus, D. 2006. The 2000 canine distemper epidemic in caspian seals (Phoca caspica): Pathology and Analysis of Contributory Factors. Vet. Pathol. 43:321-338.

[16] Lamb, R.; Parks, G. 2007.Paramixoviridae: the viruses and their replication. In: Knipe, D.; Howley, P. Fields Virology $5^{\mathrm{a}}$ ed. Lippincott Williams \& Willkins. Philadelphia, USA. pp 1449-1496.

[17] Murphy, F.; Gibbs, E.; Horizinek, M.; Studdert, M. 1999. Laboratory diagnosis of viral diseases. In: Veterinary Virology. 3a ed. Academia Press. New York, USA. Pp 193-224.

[18] Martella, V.; Elia, G.; Buonavoglia, C. 2008. Canine Distemper Virus. Vet. Clin. Small Anim. 38: $787-$ 797.

[19] Mochizuki, M.; Hashimoto, M.; Hagiwara, S.; Yoshida, Y.; Ishiguro S. 1999.Genotypes of canine distemper virus determined by analysis of the hemagglutinin genes of recent isolates from dogs in Japan.J Clin Microbiol 37(9): 2936-42.

[20] Muñoz, C. 2013. Diagnóstico molecular del virus distemper canino mediante la Reacción en Cadena de la Polimerasa asociada a transcripción inversa del gen de la proteína de la nucleocápside viral. Memoria de Título Médico Veterinario. Santiago, Chile. U. Chile, Facultad de Ciencias Veterinarias y Pecuarias. 22 p.

[21] Navarro, C. 2012. Diagnóstico del Distemper Canino. In: Simposio Internacional de Actualización en Distemper. Santiago, Chile. 6-7 agosto 2012. Instituto Neurológico. 1-35 pp.

[22] Pardo, I.; Johnson, G.; Kleiboeker, S. 2005. Phylogenetic characterization of canine distemper viruses detected in naturally infected dogs in North America. J. Clin. Microbiol. 43(10): 5009-5017.

[23] Pinotti, M.; Gollan, A.; Delgado, A.; Passeggi, C.; Occhi, H.; Blainq, L.; Canavesio, M. 2009. Distemper canino. Revista FAVET. 8(2): 29-45.

[24] Saeidnia, S.; Abdollahi, M.2013. Are other fluorescent tags used instead of ethidium bromide safer?. DARU 21(1):71.

[25] Salas, V., Pizarro, J., Navarro, C. 2018. Phylogenetic analysis of canine distemper virus detected in Chile. International Journal of Current Research. 2018; 10: 72402-72407

[26] Summers, B.; Appel, M. 1994. Aspects of canine Distemper virus and measles virus encephalomyelitis. Neuropath. Appl. Neuro. 20: 525- 534.

[27] Thermofisher Scientific.2018. Oligoperfect primer design. [en línea] https://tools.thermofisher.com/content.cfm?pageid=9716 [consulta 15-04-2018]

[28] Von Messling, V.; Oezguen, N.; Zheng, Q.; Vongpunsawad, S.; Braun, W.; Cattaneo, R. 2005. Nearby clusters of hemagglutinin residues sustain SLAM-dependent canine distemper virus entry in peripheral blood mononuclear cells. J. Virol. 79 (9): 5857-5862

[29] Yipeng, J.; Xinke, Z.; Yisheng, M.; Yanchao, Q.; Xiaobin, L.; Kaihui, Z.; Chenglin, Z.; Degui, L.; Xuelian, F.; Xinrong, X.; Yiwei, W.; Huanan, W.2017. Canine distemper viral infection threatens the giant panda population in China. J. Oncotarget. 8 (69): 113910-113919.

Citation: Navarro. C., et al., (2019). " Promising use of Polymerase Chain Reaction Associated toReverse Transcription for the Detection of the America-1 Lineage of Canine Distemper Virus ",International Journal of Research Studies in Zoology, vol. 5, no. 1, p. 18-25, 2019.DOI: http://dx.doi.org/10.20431/2454-941X.0502004

Copyright: (C) 2019 Authors. This is an open-access article distributed under the terms of the Creative Commons Attribution License, which permits unrestricted use, distribution, and reproduction in any medium, provided the original author and source are credited. 